\title{
An Analysis on Famous Brand Strategy of Economic Development
}

\author{
Qi Zhang ${ }^{1,2, a}$,Jinjiang $\mathrm{He}^{1, b^{*}}$ and Ning Cail, \\ ${ }^{1}$ School of Public Administration, Zhejiang University, Hangzhou 310058, China \\ ${ }^{2}$ Lishui University , Lishui, 323000, China

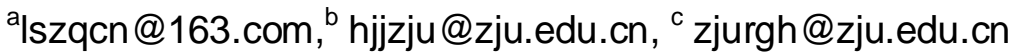 \\ *The corresponding author
}

Keyword: Economic development; Brand strategy;Famous

\begin{abstract}
In order to meet the economic development "shift speed" of the new features, implementation of brand strategy and the development of brand economy has become a boost to the city's economic development and build an economic upgrade version of one of the important path. This paper identified the implementation of brand strategy in the process of problems and countermeasures, to build the city's brand economy and promote economic restructuring and upgrading of the reference.
\end{abstract}

\section{The Brand Strategy in Hangzhou}

In recent years, the economy in Hangzhou continued rapid and healthy growth. At the same time, Hangzhou has many the Chinese brand-name products, the number of brand-name products in Zhejiang province and vice-provincial cities in a leading position, provincial brand and municipal brand training and new The forefront of the province. As of December 2013, the country has selected 339 brand-name products in China. Hangzhou has 52 Chinese brand-name products. And it is accounting for more than $15 \%$ of China's total brand-name products. Zhejiang Province has a total of 254 new brand-name products in 2013, and Hangzhou has 205 provincial-level brand-name products, the new provincial brand-name products 49 (about the total number of 1/5). Hangzhou manufacturing brand is gradually moving to the world market, promote the Hangzhou economic restructuring and accelerate the process of new industrialization, and Hangzhou to become brand-name products to support the economic strong city. From the brand-name structure, industrial brand is still an absolute advantage, but the increase has declined, agricultural brand remained stable, service industry brand showed a rapid growth trend. As of 2013, the city has 449 provincial-level industrial brand-name, city-level industrial brand 883, 2013 provincial and municipal industrial brand accounted for respectively lower than in 2012, 2013 provincial and municipal service brand new number were 27 And 23.

\section{The Top Ten Brands of Industrial Layout Gradually Optimized}

The top ten industries of the focus development in Hangzhou in recent years lead the development of the industry. Brand name in the top ten industrial structure has been gradually optimized. Hangzhou municipal government achieve goals in promoting and nurturing the top ten industry brand-name products. At the end of 2013, the city's top ten industries have more than the number of municipalities as follows: cultural and creative industries 52, tourism and leisure industry 105, financial services 6, 33 e-commerce industry, 51 information software industry, 125 advanced equipment manufacturing industry, 73 Internet of Things, 33 bio-medical industries, 54 energy-saving environmental protection industry, 81 new energy industries. During 2011 to 2013, the city's top ten industries to achieve the added value of 390.874 billion, three consecutive years of growth were greater than 10\%. And 2013 is accounting for 46.9\% of GDP. As of 2013, the city's industrial brand, equipment manufacturing, energy saving and environmental protection, information software, cultural and creative, bio-medicine and other strategic emerging industries, high-tech, high value-added brand-name products accounted for 117 , accounting for $12.3 \%$. During 
2012 - 2013, the e-commerce industry continued high-speed development trend, 2013 added value of 393.80 billion, an increase of 0.6 percentage points over the previous year, accounting for $4.7 \%$ of GDP, three-year average annual growth rate of $52.6 \%$. Cultural and creative industries to maintain rapid growth to achieve added value of 135.951 billion, the total size of the top ten key industries continue to rank first, the growth rate is higher than the city's GDP growth rate of 10 percentage points, accounting for the city's GDP ratio of $16.3 \%$. Growth rate and the proportion of GDP showed a rising trend year by year. From the industrial layout, the implementation of brand strategy to the city's modern service industry and strategic new industries to nurture and develop a better supportive role, cultural and creative, financial services, information software, tourism and leisure, e-commerce as a new advantage of Hangzhou Industry, brand-name products in the top ten industries in the rational layout of the general agreement with the information economy and the development trend of the wisdom of the economy.

\section{The Suggestions}

Increase the Leading Enterprises to Cultivate Brand-name Efforts to Enhance the Level of Direct Contribution to the Brand Economy. The goal is to create industry leaders, the formation of large enterprises as the main body, supporting the industrial structure of small and medium-sized enterprises to achieve industrial organization innovation, brand economy in size and output value has a qualitative breakthrough. In the adjustment of product structure, enterprise structure, industrial structure. According to the industrial development policy and enterprise transformation and upgrading requirements to guide key industries, key areas, key enterprises, specialty products brand training, continue to increase the traditional advantages of industry. Hangzhou City, the top ten key support industries, strategic emerging industries, service industry, the city's top ten leading agricultural industry, industrial cluster demonstration area of brand-name cultivation efforts to encourage independent intellectual property rights or high-tech products, energy-saving environmental protection products to create brand-name. By optimizing the city's brand-name evaluation mechanism and evaluation content, we pay more attention to the quality of enterprises, efficiency, development, social responsibility and other content, intellectual property rights, technological innovation, brand cultivation and other prominent enterprises to policy tilt, so as to screen out a number of competitiveness that play the important role of the city's economic transformation and upgrading. We support industrial enterprises to carry out their own brand building, guidance and promote the creation of corporate brand planning work.

Step Up the Promotion of Brand-name Economic Structure Transformation and Upgrading, Highlighting the City's Brand Economy Demonstration Effect. The transformation and upgrading of the city economy should adhere to the innovation take the use of the environment and elements of the two elements of the mechanism, the establishment of modern industrial system. First, adjust and optimize the industrial structure, and focus on nurturing the top ten strategic industries. Second, the implementation of "four for three" strategy, crack the city's economic structure. Third, promote the "two" deep integration, and expand the wisdom of the industry and information industry. Promote the infiltration of information technology in the industrial field, improve the brand name of the information technology content and value-added, to promote brand-name products to the value chain high-end cross.

Speed Up the Implementation of Cluster Regional Brand Strategy Construction, Play Brand-name Economic Growth Aggregation Effect. We should introduce "Zhejiang manufacturing", cluster regional brands and the development of Hangzhou characteristics of industrial clusters and other ideas to promote the city from the "quantity of economy" to "brand economy" transformation, accelerate the promotion of enterprises from the unlicensed, OEM to independent brand changes, from a small amount brand to a large number of brands, from its own brand to the famous brand across. In the development of product brands and corporate brands on the basis of the brand to create collective action to further cultivate a greater influence on the regional brands (such as collective brands, collective reporting, registration of origin, etc.). Create a well known brand to drive regional brands. The city should continue to adhere to the characteristics of 
development, and actively cultivate product brands, industry brands, regional brands in the consolidation and development of industrial characteristics, cultural characteristics. The establishment of well-known brands and regional brand development incentives to nurture the formation of a number of quality brands with the core competitiveness of the advantages of enterprises and industrial clusters. Cultivate the provincial industrial brands, famous trademarks, well-known firms to promote a number of products and enterprises among the ranks of well-known national brands.

Promote the Development of Green Economy, Build a Harmonious Industrial Environment Nurturing Economic Transformation and Upgrading. Depth implementation of the "industrial city" strategy, and actively use high-tech, advanced and applicable technology, especially information technology transformation to enhance the traditional advantages of industry. To further accelerate the adjustment of industrial structure, the establishment of "per-mu benefits", energy consumption, sewage dumping mechanism to speed up the elimination of backward production capacity and strict control of high energy consumption projects, the implementation of brand strategy to support research and development, headquarters and other emerging formats according to industry development and space planning land use plan. Further support the development of small and medium enterprises to speed up the massive economy to modern industrial clusters change, get rid of the value chain on the "low-end lock." Conscientiously implement the industrial restructuring and revitalization plan, and further bigger and stronger textile and silk, automobile and parts, light industry and other traditional industries, improve the level of manufacturing and competitiveness, and promote the manufacturing market to the manufacturing industry to change the market.

Construction of "beautiful Hangzhou" to create a harmonious industrial environment, "beautiful Hangzhou" three-year action plan to achieve the goal is to achieve a beautiful, green low-carbon, livable comfort, natural law, happiness and harmony as the main symbol. Under the influence of this strategy, the municipal government should actively guide enterprises to invest in the construction of "beautiful Hangzhou", guide and corporate social environmental protection and cleaner production, civic ecological civilization knowledge and literacy training, strengthen the low-carbon brand products and brand-name products support and recognition.

\section{Acknowledgements}

This research was supported by Zhejiang Provincial Natural Science Foundation of China: Study on the generating mechanism of corporate strategic entrepreneurship: viewing from a perspective of network reconfiguration. NO. Y17G020006.

\section{References}

[1] Zhang R. Famous Brand Strategy[J]. Electronics Quality, 1995.

[2] Qiu X. Ten Contents' Analysis on the World Famous Sports Products and Countermeasures about How to Implemnt Brand Strategy[J]. Journal of Chengdu Physical Education Institute, 2003.

[3] Y P, Xing H J, Jiang X G. Morden Enterprise Famous Brand Strategy Effect[J]. Boiler Manufacturing, 2003.

[4] Zeng H. Discuss on Famous-brand Strategy and Sports Goods Standardization[J]. Journal of Chengdu Physical Education Institute, 2002.

[5] Zhang M X. Insight into Famous Brand Strategy in Psychological Perspective[J]. Theory \& Practice of Trade Unions, 2005.

[6] Jingfeng L U, Cheng P. Consideration of Execution of Culture Famous Brand Strategy on Sport-Goods Trade in Our Country[J]. Journal of Xian Institute of Physical Education, 2003. 